When Urban Greening Becomes an Accumulation Strategy

Exploring the Ecological, Social and Economic Calculus of the High Line

Gulsrud, Natalie Marie; Steiner, Henriette

Published in:

Journal of Landscape Architecture

DOI:

10.1080/18626033.2019.1705591

Publication date:

2020

Document version

Peer reviewed version

Citation for published version (APA):

Gulsrud, N. M., \& Steiner, H. (2020). When Urban Greening Becomes an Accumulation Strategy: Exploring the Ecological, Social and Economic Calculus of the High Line. Journal of Landscape Architecture, 14(3), 82-87. https://doi.org/10.1080/18626033.2019.1705591 


\title{
When urban greening becomes an accumulation strategy: Exploring the ecological, social and economic calculus of the High Line
}

\author{
Natalie Gulsrud and Henriette Steiner University of Copenhagen, Denmark
}

\begin{abstract}
The canonical design project the High Line is built on an abandoned elevated freightrail structure that winds through some of New York City's largest post-industrial districts. With over 80 million visits since its opening in 2009, the High Line is one of the world's most visited urban parks. The product of a collaboration spearheaded by landscape architect James Corner, it has become one of the most celebrated symbols of landscape urbanism. Despite its enormous success and widespread acclaim, the High Line has also been criticized for its inattention to issues of equality. Our contribution is to unpack how the neoliberal logic implicit in the High Line effect is delivered as a process of socioecological subtraction that ultimately leads to the accumulation of capital for a select few, and to ask how urban designers might rethink the High Line model to take into account more redistributive principles of justice. What might a just production of urban nature look like, and for whom?
\end{abstract}

\section{Keywords}

Landscape urbanism / High Line effect / environmental justice

From New York to Singapore, cities the world over are profiling themselves as green and environmentally friendly to promise better quality of life, promote sustainable development and increase their competitive advantage. In this quest, there has been an increasing global focus on urban greening-by transforming post-industrial topographies into parks, for example. Landscape urbanism has emerged as a critical movement in this trend, introducing ecologically robust landscapes to the urban fabric, providing site-specific and holistic 'nature-based solutions' that address pressing urban-environmental problems while also affording an aesthetic boost to a particular area. ${ }^{1}$ Ecology in this context takes the form of infrastructure that feeds into cities seen as complex systems, and that ties together ecological, economic and social aspects. When the city is seen as a system in this way, urban greening can arguably become a method for achieving resilience. Resilience is understood here as the balance required to support cultural and ecological systems, and resilience thinking can promote urban landscapes that accommodate cycles of disruption and reorganization with multifunctional ecological, economic and social co-benefits, such as better air and water quality, improved storm water management, social cohesion and increased human health, well-being and value generation. ${ }^{2}$ However, it is very challenging to apply a socioecological agenda to resilient landscapes, and to reframe resilience benefits as community- and people-focused. While resilience thinking offers a dynamic and holistic approach to human and environmental change, it problematically assumes that social and ecological dynamics can be modelled similarly, and thus it can occlude important questions about the role of power and culture in the ecological calculus of urban greening. ${ }^{3}$ This calculus itself entails a form of ontological flattening that privileges economically accumulative relationships over attention to differentiation or meaning. ${ }^{4}$ 
One project that arguably exemplifies the principles of landscape urbanism and the underlying narrative of resilience thinking is the now canonical High Line in the West Chelsea neighbourhood of Manhattan. ${ }^{5}$ With over 80 million visits since its opening in $2009,{ }^{6}$ the High Line is one of the world's most visited urban parks. The product of a collaboration between James Corner (of James Corner Field Operations) and architecture firm Diller Scofidio + Renfro, with a planting design by Piet Oudolf, it has become a celebrated symbol of landscape urbanism. The park is built on a 1.45-mile-long (2.3-km-long) elevated freight rail structure on Manhattan's West Side, standing 30 feet $(9 \mathrm{~m})$ above the ground and winding through large postindustrial districts. The park's design foregrounds the appropriation and transformation of post-industrial transport and ecological networks. The result is a performative metropolitan park experience that draws heavily on the amalgamation of natural, social and economic parameters in one large calculus whereby urban greening is successfully employed as an accumulation strategy. We see the wider story of the project's success as framed not only by the ecological aesthetic of the park, but also by the quantitative narrative of capital and people metaphorically and literally flowing towards the High Line since the park's opening-measured, for example, in the increasing visitor numbers, retail transactions and real estate prices in the area.

Many critics have praised the community-driven spirit of the High Line project while acknowledging the complex and interlinked social, political and ecological dynamics of urban greening strategies. The site has been hailed as a 'model of urban regeneration' developed in collaboration with citizens, politicians and top-tier designers 'across fields and perspectives'. ${ }^{7}$ The park is owned by the City of New York, but it is programmed, managed and operated in partnership with the local notfor-profit group Friends of the High Line, who raise 100 per cent of the park's operating budget each year. The group maintains a broad agenda to support inclusiveness and education-for example, using staff resources to educate local children about the intersections of ecology, design and public art, or establishing community gardens across the city that focus on inclusion, environmental justice and urban greening. ${ }^{8}$ Since the High Line opened as a public park, the surrounding neighbourhood has experienced a cultural and economic renaissance, leading to what some design critics have called the 'High Line effect', with more than sixty cities across the world-from Liverpool to Sydney and Seoul-replicating the process to achieve the same benefits in ecological, social and economic terms as the area around the High Line. ${ }^{9}$ Yet, this economic upturn has gone hand in hand with drastic neighbourhood upheaval and displacement, raising questions about which community the High Line actually serves, and what the role of urban greening is in the High Line process. ${ }^{10}$

Despite its enormous success and widespread acclaim by designers, politicians and the public, the project has been heavily criticized in relation to issues of equity and social justice. ${ }^{11} \mathrm{~A}$ particular point of contention is that although the design logic behind the park's post-industrial nature has provided an aesthetic boost, it has also intensified pre-existing uneven socioeconomic patterns in the area. ${ }^{12}$ Along these lines, we propose that the project has engaged in a complex process of socioecological calculus, a process of subtraction and addition ${ }^{13}$ in which people and nature with less economic value have been subtracted from the landscape to make space for new forms of people-nature interaction, namely those with the potential to generate more capital value. Here, one can argue that the High Line, with its dynamic and community-driven reuse of a notorious post-industrial structure, has attempted to 
reframe conventional ecological design approaches by bridging technological strategies with socioecological principles, such as human well-being and communitybased governance models for urban greening.

Indeed, the High Line is set to generate $\$ 1$ billion dollars in tax revenues for the City of New York over the next twenty years, ${ }^{14}$ and it has actively contributed to an ongoing upheaval whereby luxury condos have replaced middle-class housing, displacing large swaths of the neighbourhood. ${ }^{15}$ In light of the High Line's example of the potential of ecological design to unleash previously unknown economic forces, in this article we critically review the effects of these contestations and complexities, and we ask how landscape urbanism can account for these socioecological power dynamics going forward. We therefore end the article by reflecting upon the kind of social and political power it will take to realize more just nature-based solutions.

The High Line design programme continues to be celebrated and replicated on a global scale across diverse and uneven sociopolitical arrangements. We would therefore like to take the opportunity in this article to engage with the overall impact of a design model that places the commodification of urban greening front and centre. We do this after multiple visits to the structure-most recently in November 2018, a visit from which we include some snapshots in this article. We have been among the many people who have relished the ways the High Line has opened the urban fabric of Manhattan up for walking and visual consumption in new ways. The striking performativity of the High Line supports a dynamic form of metropolitanism that promises socioecological interactions in the car-less street, and conversations under the sky to the sounds of fluttering leaves and rustling grasses. But we also explore the nagging feeling that as we engage in these interactions and conversations, we ourselves become part of the scenery; that our bodies, vision and eagerness to consume the experience are key to its making. The design critique is an opportunity to begin to explore some facets of these ambiguous feelings. Our contribution is to unpack how the neoliberal logic implicit in the High Line effect is delivered as a process of socioecological subtraction that ultimately leads to the accumulation of capital for a select few, and to ask how urban designers might rethink the High Line model to take more redistributive principles of justice into account. What might a just production of urban nature look like, and for whom?

Before taking up this discussion, let us first go back in time and ask what kind of past is established as the design's moral baseline. As we will see, this past feeds into the narrative of Manhattan's recent successful urban regeneration, and it thereby becomes not just a pictorial reference within the design, but an allegory of how urban greening can be used as an accumulation strategy.

\section{A performative space}

By the 1990s, the shipping and manufacturing industries had exited Manhattan, and New York could no longer be called an industrial city. ${ }^{16}$ The city's post-industrial skeleton had enormous cultural and economic appeal, and developers were keen to begin work in West Chelsea. The High Line rail viaduct was central to discussions about how this neighbourhood should, could and would be transformed in a period of gentrification. Following the economic recession of the 1970 s and 1980 s, successive waves of gentrification notably attracted gay men, lesbians and artists to the area. In the late 1980s, upper-middle-class urban elites from the financial sector began to populate the neighbourhood. This meant that by the 1990s, middle-class families not 
protected by rent control had been priced out; by the turn of the century, when luxury condos began to sprout in the area, property prices were exploding. ${ }^{17}$

Although the redevelopment of the High Line should not be singled out as the instigator of continued gentrification in West Chelsea, the structure played a central role in debates on how the area would develop. Many private developers, along with the city itself under Mayor Giuliani in the 1990s, moved to demolish the structure; this was contested by the local community, who believed it provided protection against gentrification. ${ }^{18}$ It was in this context that the Friends of the High Line formed to campaign for the preservation of the rail corridor, in the name of both 'green' community identity and economic development. The group successfully lobbied for the preservation and redevelopment of the High Line, using legal measures in combination with sophisticated political manoeuvring-by ensuring increased development rights for property owners along the corridor, for example.

In this process, the interests of particular, highly socioeconomically empowered groups became the points of reference around which the new public park was designed. In parallel, the site was branded as a place of 'queer natures'-a reference both to the queer fringe community that was often associated with the site and to the transgressive weed species that grew out of the structure's industrial fabric - and with this the design project began to take form. ${ }^{19}$ This narrative was reflected in the project in sophisticated ways: landscape urbanism, as expressed by the designers, initiated a complex process of ecological subtraction and addition. Inspired by the concept of abandonment, the design team allowed the structure to reveal itself through a permeated concrete carpet running the length of the High Line. This was designed to allow the plants to disturb and break through the pavement, profiting from diverse microclimates along the corridor. Corner and team selected plants with a focus on 'native, drought-tolerant, and low-maintenance species', arranged according to naturally occurring plant communities in the self-seeded High Line landscape. ${ }^{20}$

The official winning submission detailed how the design, inspired by the 'melancholic, unruly beauty' of the post-industrial and self-seeded High Line structure, aimed to change the 'rules of engagement between plant life and pedestrians' by accommodating 'the wild, the cultivated, the intimate, and the hypersocial' while also 'providing flexibility and responsiveness to the changing needs, opportunities, and desires' of the dynamic urban context. ${ }^{21}$ It would have been pertinent to explore in more depth what was actually meant by categories such as 'wild', 'hyper-social' and 'desires', or by dualisms such as human/non-human, wild/cultivated and intimate/social. What the design brief did not reveal, however, was that although native plants had been selected for the park, the self-seeded landscape on which the design was based was to be wholly eliminated in the name of a steered urban greening process. The elimination included unsavoury or unruly species such as Ailanthus altissima (tree of heaven), an iconic and widespread tree featured in Joel Sternfeld's depictions of the High Line's fallow landscape. Although seeds from this fallow landscape were used to germinate plant families in the designed park corridor, the eco-logic behind the plant design has sparked critique: the current plantings on the High Line are sensitive, and require intensive maintenance and watering compared with its previous uncultivated ecology. The ecological subtraction of an unruly meadow and shrub landscape that did not deliver economic returns thus cleared a space for the addition of costly green growth, both in and alongside the park, in the name of capitalist reproduction. 
The process of sociocultural subtraction is also evident in the park's design, which allows few activities except walking and gazing, and is surrounded by upscale boutiques and artisan groceries catering to a very particular segment of the urban populace. According to some analyses, despite the high numbers of visitors to the structure, it is rarely frequented by residents of the nearby public housing. ${ }^{22}$ Thus we can read the redevelopment of the High Line as much more than just a dynamic of economic development: there is a distinct clash between different sets of political and economic interests, in a way that suggests a winning party.

If we take the changing uses of the High Line as a metonym for the changing urban culture of New York City in the twentieth century, they reflect shifts in capital whereby people instead of freight become the most valuable resource in a post-industrial city. Unsurprisingly, in neoliberal discourse, some people-those who actively contribute to the knowledge economy-count more than others, just as certain plants and spaces are preferred over others. This criticism has often been voiced in relation to the High Line in particular and landscape urbanism more generally. ${ }^{23}$ There is thus an inherent conflict within the process of socioecological subtraction that underlies the High Line as an urban greening project-even though the project meets all the ideals about creating liveable and lively public spaces that add social and capital value to an area. The elimination of certain types of landscape heritage traces from the space has engendered a new socioecological hierarchy in the project, and a transformed materiality in the urban fabric of Manhattan. The green brand of the High Line has subsumed Chelsea's formerly anarchic neighbourhood vibe and that this is deeply interconnected with the urban greening project is visible in the metaphors describing this process; the sterile ecology of the park has silenced the queer nature of the post-industrial site, corporate partnerships have eroded grassroots activism. The neoliberal calculus of the High Line is insidious and unavoidable, as the design intervention has restructured the daily interactions of the High Line's human and non-human inhabitants, rendering people's behaviours and interactions with plants an invisible yet potent commodity. As visitors to the site, we co-produce and reinforce the design intervention's success story as one where urban greening is the spark for capital accumulation.

Few can deny, however, that it is a spectacular experience to walk along the High Line, above the city and between buildings. We ourselves are among the many who have taken great pleasure in the experience. The High Line frames and directs the gaze in a way that generates an aesthetic experience focused on a very specific kind of consumption, nurturing a heightened sense of voyeurism. Importantly, however, this gaze is a guided, passive one: it can immerse itself in all of the additions, but it is unable to grasp what has been subtracted. Moreover, the High Line's various framing devices have the effect of flattening the cityscape behind them. As one walks down the High Line, the city becomes simultaneously mise en scène and scenery. As social scientists Julia Rothenberg and Steve Lang argue, in the post-industrial context of West Chelsea, we may regard this as a way of 'turning the upheaval and displacement produced by neoliberal urbanism into a series of disconnected surface effects or "episodes" which normalize and naturalize inequalities'. ${ }^{24}$

\section{Reconciling upheaval and regeneration}

By moving to reconcile nature and urban development, landscape urbanism responds to the challenges that cities currently face, delivering projects (such as the High Line) with integrated technological and ecological visions of climate-resilient 
metropolitanism. Urban greening is increasingly used to conceive a form of 'socially accountable' economic restructuring in the name of liveability and overall climate resilience. ${ }^{25}$ However, its implementation can lead to the reconfiguration and exacerbation of socioeconomic inequalities. ${ }^{26}$ Our discussion of the history of the High Line emphasizes that urban greening is at the centre of contestation and resistance by residents and civil society groups, as it can be co-opted to serve diverging and sometimes oppressive interests. If the quest for urban greening (as a quantitative measure) takes on a critical role in determining the social, ecological and economic configuration of urban landscapes, there is a serious need to take account of principles of environmental justice in the design and governance of urban greening in ways that account for meanings that are impossible to measure-and that we have nevertheless tried to pinpoint in this analysis as a negative impact of subtraction. A first step would be to challenge design principles to refocus: away from measurable aesthetic, ecological and technological purity and effects, and towards frameworks of distributional, procedural and representative justice in cities.

Environmental justice attends to the processes through which environmental inequalities arise and are maintained. ${ }^{27}$ Activists and scholars have long called for the realization of environmental justice not just in health and environmental policy, but also in landscape planning and urban park management. Landscape architects could interrogate and promote more than just urban renaturing by beginning to take account of the spatial allocation of 'goods' and 'bads' in relation to socioeconomic attributes. This could be done through historical and contextual explorations and differentiations of the terms by which interest- and identity-based groups (human and non-human) are included in ways that are meaningful to them. Furthermore, designers could more actively incorporate platforms for participatory decision making into their design processes, thereby deliberately highlighting issues of inclusion, exclusion and differentiation. Such thinking could open up ongoing and contested discussions of how environmental transformation is not simply a function of technological change or economic growth, but involves a distinct clash between different sets of political and economic interests, with clear winners and losers.

The impact of the High Line as a material construct has enabled not just different kinds of human activity, but also different kinds of greening throughout the years. The most recent chapter in its history gave the place global visibility and unleashed hitherto unknown economic forces. It did so through a project where the design gesture and principles behind landscape urbanism gave rise to processes of social, ecological and economic subtraction and addition. The impact suggests an ontological levelling of the structure and its human and non-human inhabitants to an accumulation of relationships with the city-social, ecological and economic. As urban greening is increasingly engaged in as an accumulation strategy, urban design will do well to ask hard questions not only about sites, but also about those whom sites serve.

We are not the first to study this structure. Indeed, the High Line has been thoroughly reviewed, studied and critiqued, including with regard to environmental gentrification and socioecological conflict. ${ }^{28}$ In line with scholars who argue for the realization of environmental justice in landscape planning and urban park management, ${ }^{29}$ we are concerned with how urban greening is politically and economically mobilized and socially appropriated to produce environments that embody positions of social power, even while masking those positions as an accumulation of relationships that can be measured. Behind the ostensibly win-win situations that result from such accumulation strategies, questions rear their heads 
about who wins and who loses from urban greening. The scope of this article has allowed us to broach this discussion through some examples in relation to a single case study, and we have tapped into a larger base of historical and contextual explorations of how some participants (human and non-human) are included in the High Line's design in ways that may seem more or less meaningful. Nevertheless, the very idea of a socioecological calculus places a moral onus not only on the designers, but also on the site's visitors, critics and fans, and local residents. These groups, too, help to foster an urban culture of addition and subtraction that places environmental transformation in a bigger picture than the ideas of technological change or economic growth would imply. The enduring impact of the High Line for scholars, practitioners, residents and visitors is that it forces us to participate in the distinctive marks of our moment's urban regeneration, and to interrogate its effects in the contested form of power the High Line continues to hold.

\section{Notes}

\section{Biographical notes}

Natalie Gulsrud is an assistant professor in the Section for Landscape Architecture and Planning of the University of Copenhagen. She studies the governance of urban green infrastructure to advance sustainable and just pathways to climate resilience. Her forthcoming book, co-authored with Jason Henderson, is Street Fights in Copenhagen: Bicycle and Car Politics in a Green Mobility City, to be published by Routledge.

Henriette Steiner is an associate professor in the Section for Landscape Architecture and Planning of the University of Copenhagen. She holds a PhD in Architecture from Cambridge University, UK. Her research investigates the cultural role and meaning of architecture, cities and landscapes. Her forthcoming book, cowritten with Kristin Veel, is A Tale of Two Towers: Gigantism in Architectural and Digital Culture, to be published by MIT Press.

\section{Contact}

Natalie Gulsrud

University of Copenhagen, Section for Landscape Architecture and Planning

Rolighedsvej 23, 1958 Frederiksberg, Denmark

nagu@ign.ku.dk

Henriette Steiner

University of Copenhagen, Section for Landscape Architecture and Planning

Rolighedsvej 23, 1958 Frederiksberg, Denmark

hst@ign.ku.dk

\section{Captions}

Figure 1:

The permeated concrete carpet.

(c) Henriette Steiner 


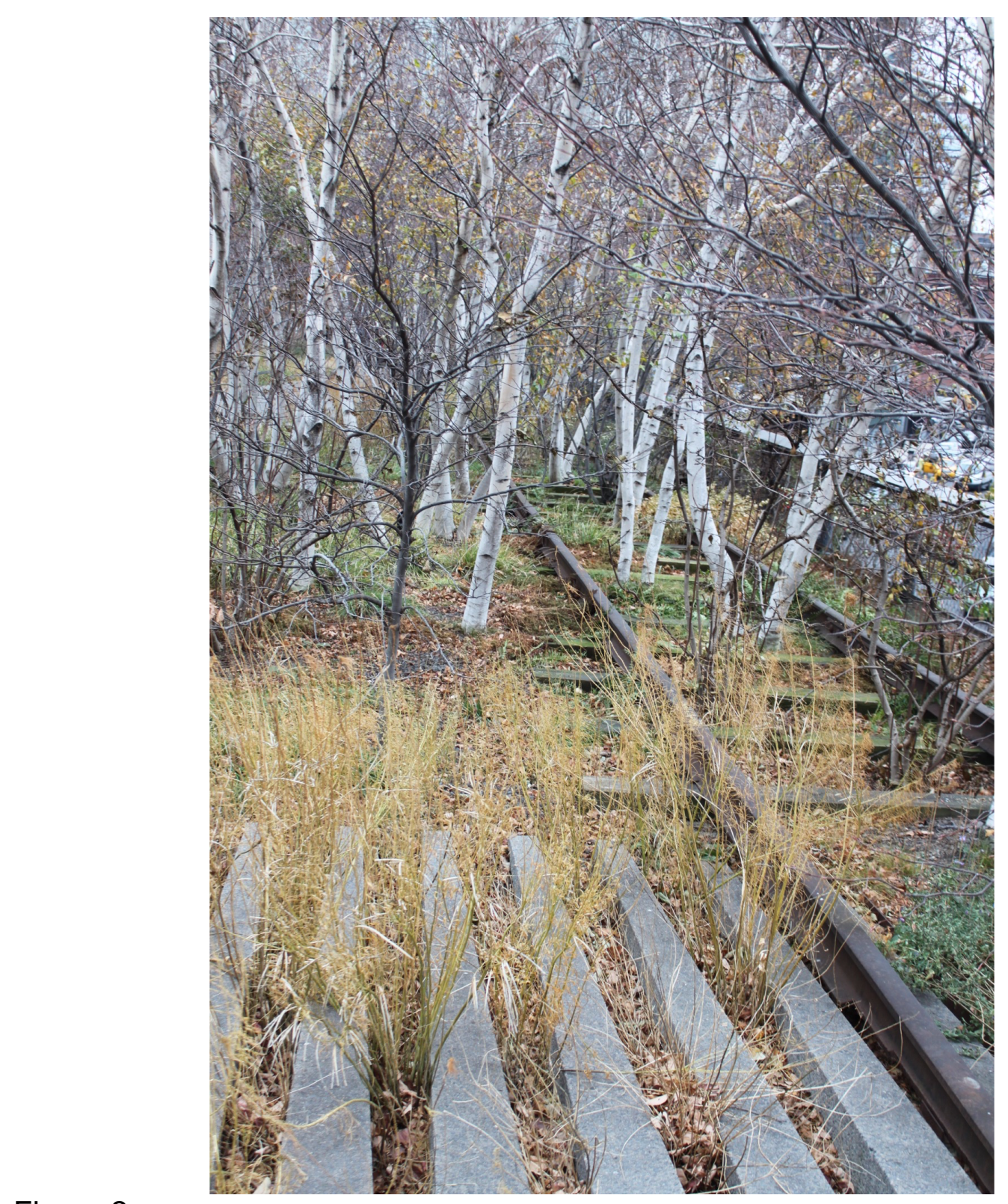

Figure 2:

Urban greening in the winter time, an elevated view.

(C) Henriette Steiner 


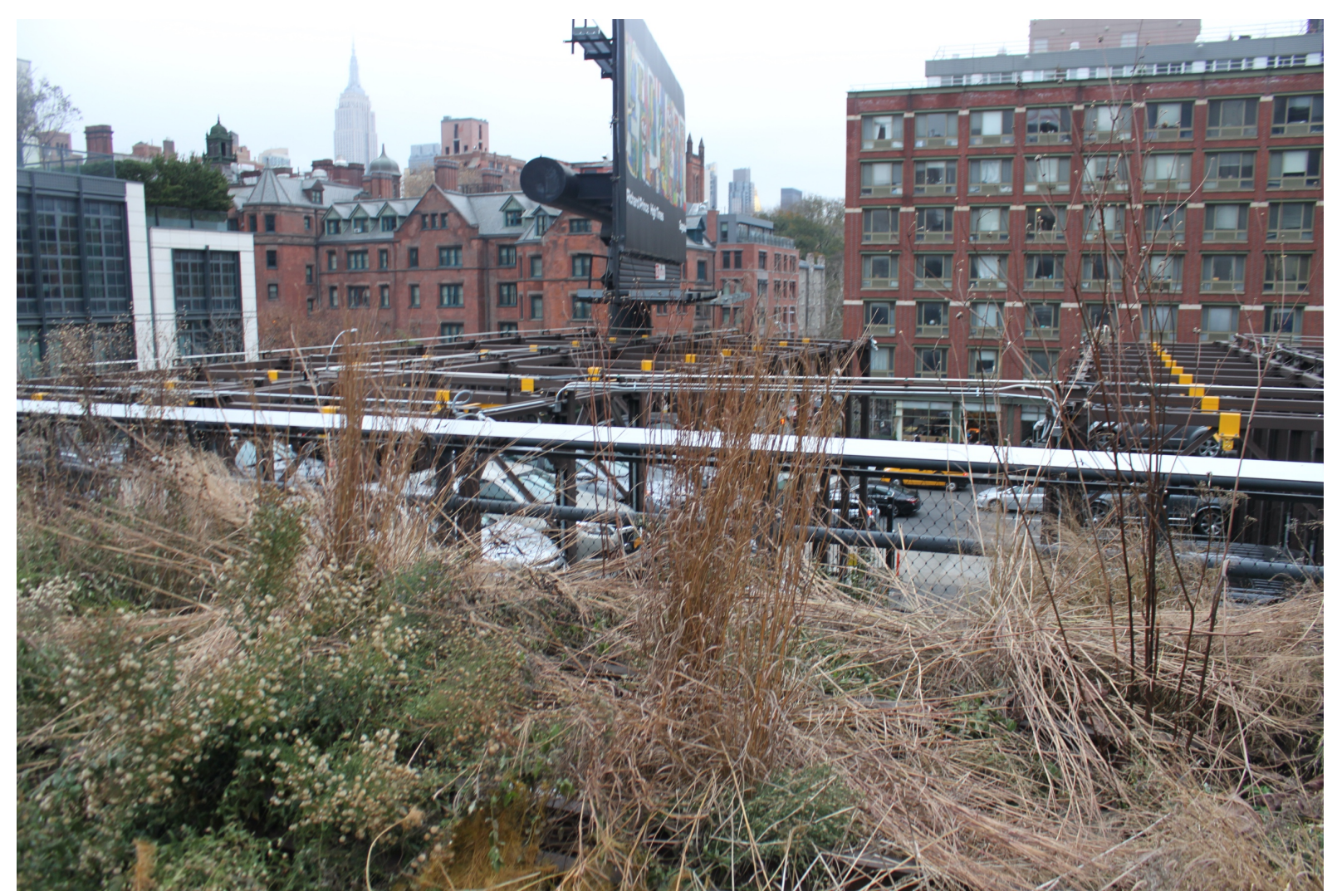

Figure 3:

Child's gaze and the city as spectacle.

(C) Henriette Steiner 


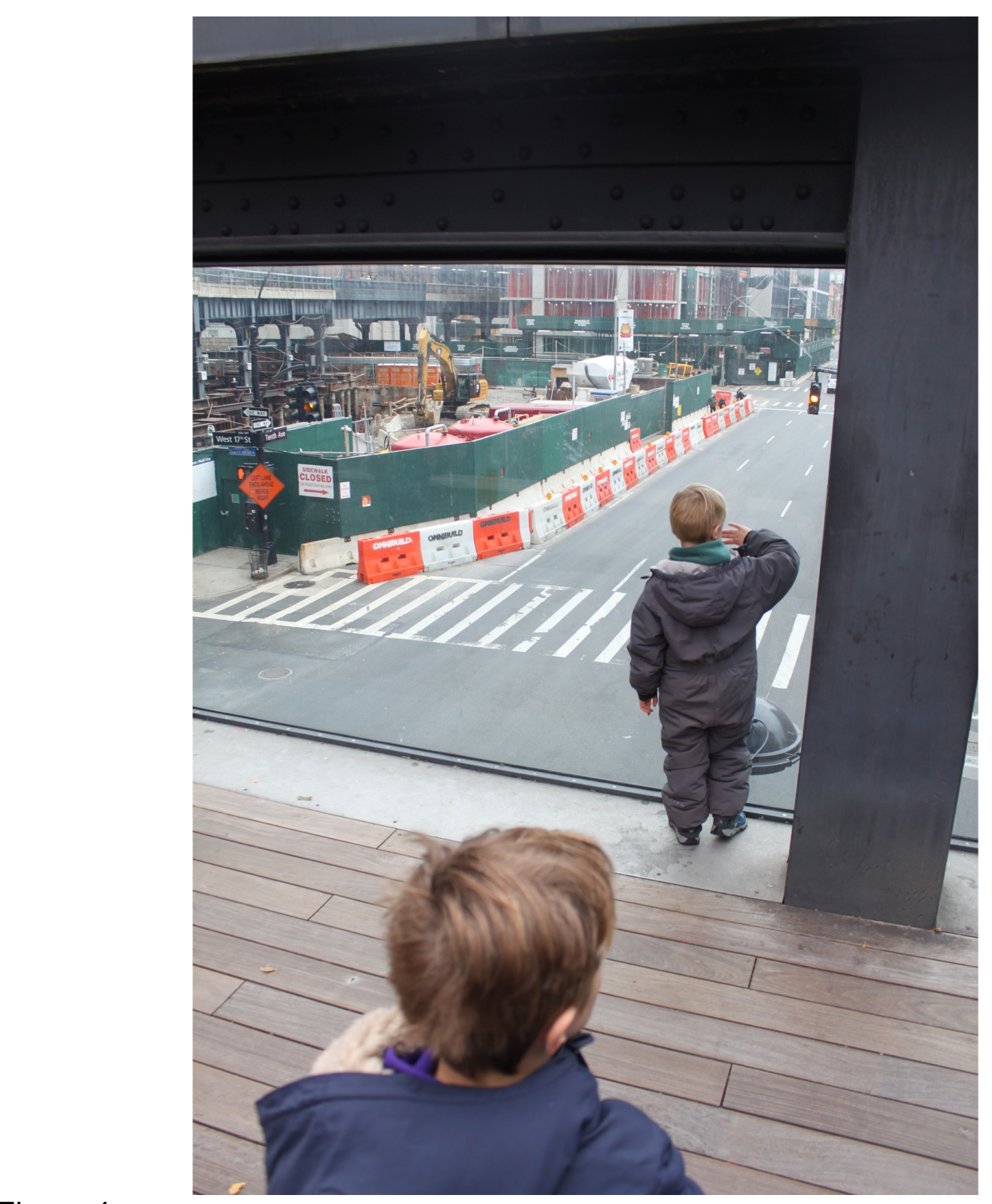

Figure 4:

Social activities on the High Line.

(c) Henriette Steiner 


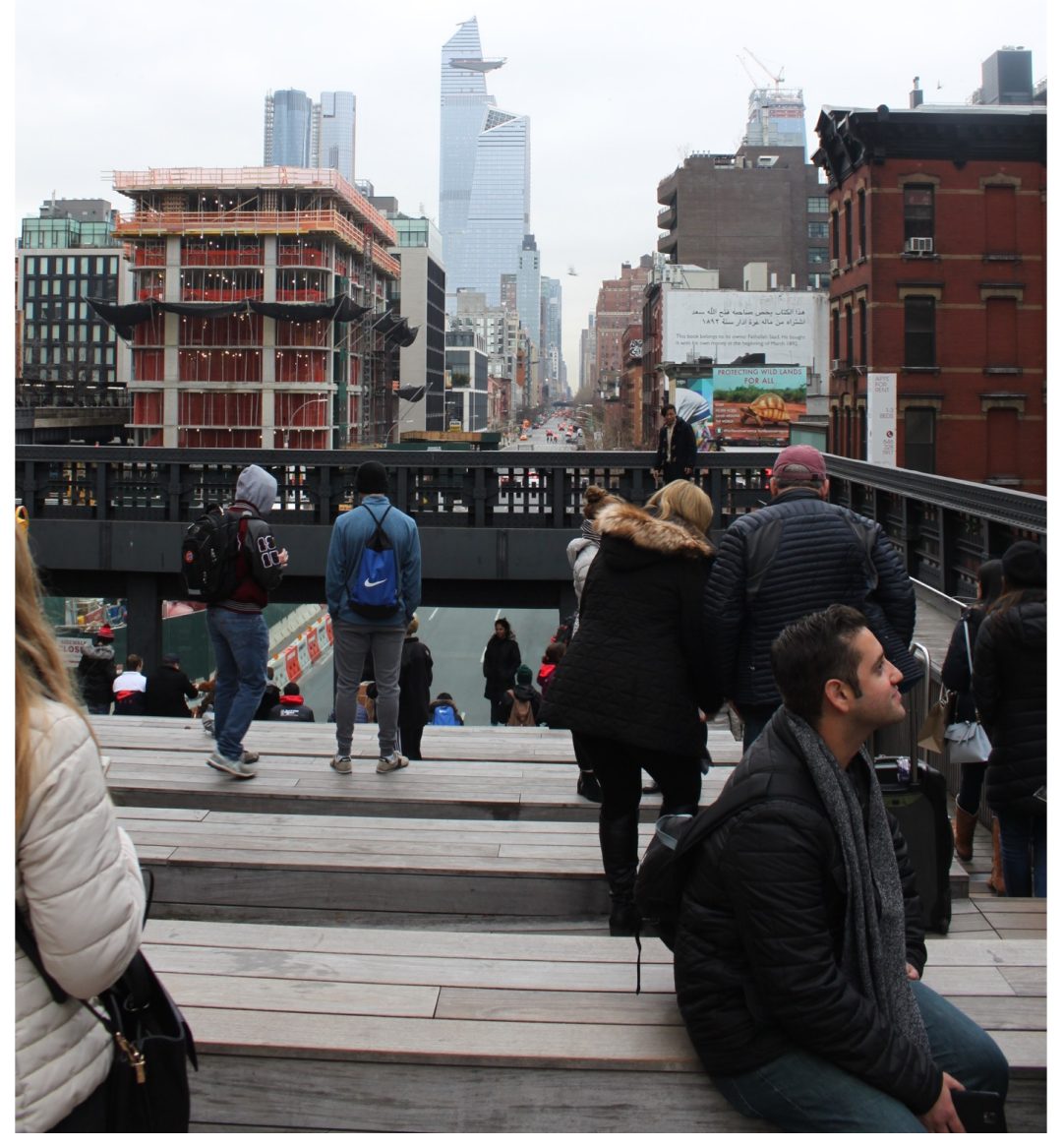

1 Charles Waldheim (ed.), The Landscape Urbanism Reader (New York: Princeton Architectural Press, 2006).

2 Carsten Nesshöver et al., 'The Science, Policy and Practice of Nature-Based Solutions: An Interdisciplinary Perspective', Science of the Total Environment 579 (2016), 1215-1227.

3 Natalie Marie Gulsrud, Kelly Hertzog and Ian Shears, 'Innovative Urban Forestry Governance in Melbourne? Investigating "Green Placemaking" as a Nature-Based Solution', Environmental Research 161 (2018), 158-167.

4 Henriette Steiner, 'I Never Promised You a Rose Garden . . .: Trapped in a Gorgeous Meadow in Copenhagen', in: Henriette Steiner, History of the Human Sciences (forthcoming).

5 Steven Lang and Julia Rothenberg, 'Neoliberal Urbanism, Public Space, and the Greening of the Growth Machine: New York City's High Line Park', Environment and 
Planning A: Economy and Space 49/8 (2017), 1743-1761; Julia Rothenberg and Steve Lang, 'Repurposing the High Line: Aesthetic Experience and Contradiction in West Chelsea', City, Culture and Society 9 (2017), 1-12.

6 Harvard University Graduate School of Design, 'High Line Wins 2017 Veronica Rudge Green Prize in Urban Design-Harvard Graduate School of Design', www.gsd.harvard.edu/2018/02/high-line-wins-2017-veronica-rudge-green-prize-inurban-design/, accessed 22 March 2019.

7 lbid.

8 Friends of the High Line, 'Community Parks Initiative: The High Line', www.thehighline.org/community-parks-initiative/, accessed 22 March 2019.

9 Hanna Erixon Aalto and Henrik Ernstson, 'Of Plants, High Lines and Horses: Civic Groups and Designers in the Relational Articulation of Values of Urban Natures', Landscape and Urban Planning 157 (2017), 309-321; Juhyeon Park and Jeongseob Kim, 'Economic Impacts of a Linear Urban Park on Local Businesses: The Case of Gyeongui Line Forest Park in Seoul', Landscape and Urban Planning 181 (2019), 139-147; James Corner Field Operations and Diller Scofidio + Renfro, The High Line: Foreseen, Unforeseen (New York: Phaidon Press, 2015).

10 Darren J. Patrick, 'The Matter of Displacement: A Queer Urban Ecology of New York City's High Line', Social and Cultural Geography 15/8 (2014), 920-941.

11 Rothenberg and Lang, 'Repurposing the High Line', op. cit. (note 5).

12 Neil Smith, 'Nature as Accumulation Strategy', Socialist Register 43 (2007), 19_ 41.

13 We draw here on Keller Easterling, Subtraction (Berlin: Sternberg Press, 2014).

14 Adam Ganser, 'Big Data and Parks', High Line Blog (18 January 2017), www.thehighline.org/blog/2017/01/18/high-line-magazine-b1g-daa-and-parks/.

15 Rothenberg and Lang, 'Repurposing the High Line', op. cit. (note 5).

16 Christopher D. Brazee and Jennifer L. Most, 'West Chelsea Historic District Designation Report', New York City Landmarks Preservation Commission (2008), www.neighborhoodpreservationcenter.org/db/bb_files/2008WestChelseaHistoricDistri ct.pdf.

17 Rothenberg and Lang, 'Repurposing the High Line', op. cit. (note 5). For a contextualized account of gentrification in West Chelsea relative to overall patterns of gentrification in New York, see Patrick, 'The Matter of Displacement', op. cit. (note 10); Lang and Rothenberg, 'Neoliberal Urbanism', op. cit. (note 5).

18 Jonathan M. Broder, 'Deconstructing New York City's High Line Park: The How, Why and Wherefore', Journal of Transportation Law, Logistics and Policy 79/3 (2012), 245-252.

19 Matthew Gandy, 'Queer Ecology: Nature, Sexuality, and Heterotopic Alliances', Environment and Planning D: Society and Space 30/4 (2012), 727-747.

20 Patrick, 'The Matter of Displacement', op. cit. (note 10).

21 lbid., 933. 
22 Rothenberg and Lang, 'Repurposing the High Line', op. cit. (note 5).

23 Pier Luigi Sacco et al., 'Gentrification as Space Domestication: The High Line Art Case', Urban Geography (2018), 1-26; Patrick, 'The Matter of Displacement', op. cit. (note 10).

24 Rothenberg and Lang, 'Repurposing the High Line', op. cit. (note 5), 8.

25 Corina McKendry and Nik Janos, 'Greening the Industrial City: Equity, Environment, and Economic Growth in Seattle and Chicago', International Environmental Agreements: Politics, Law and Economics 15/1 (2015), 45-60.

26 Isabelle Anguelovski, 'From Toxic Sites to Parks as (Green) LULUs? New Challenges of Inequity, Privilege, Gentrification, and Exclusion for Urban Environmental Justice', CPL Bibliography 31/1 (2016), 23-36.

27 Alejandro Colsa Perez et al., 'Evolution of the Environmental Justice Movement: Activism, Formalization and Differentiation', Environmental Research Letters 10 (2015).

28 See, for example, the following: Patrick, 'The Matter of Displacement', op. cit. (note 10); Nate Millington, 'From Urban Scar to "Park in the Sky": Terrain Vague, Urban Design, and the Remaking of New York City's High Line Park', Environment and Planning A 47 (2015), 2324-2338; Christoph Lindner and Brian Rosa,

Deconstructing the High Line: Postindustrial Urbanism and the Rise of the Elevated Park (New Brunswick: Rutgers University Press, 2017); Rothenberg and Lang, 'Repurposing the High Line', op. cit. (note 5); Sacco et al., 'Gentrification as Space Domestication', op. cit. (note 23).

29 Rebecca Leigh Rutt and Natalie Marie Gulsrud, 'Green Justice in the City: A New Agenda for Urban Green Space Research in Europe', Urban Forestry and Urban Greening 19 (2016), 123-127. 